\title{
EL REGIMEN LOCAL DE LA PRIMERA RESTAURACION
}

352 (094)

por

\author{
Juan-Luis de Simón Tobalina
}

SUMARIO: ANTECEDENTES HISTORICOS ANTERIORES A LA ERA CONSTITUCIONAL.-II. LA DEMOCRACIA MUNICIPAL A PARTIR DE LA CONSTITUCION DE CADIZ.-III. EL REGIMEN LOCAL DE LA REVOLUCION DE 1868. - IV. EL REGIMEN LOCAL EN LA CONSTITUCION DE 1876.- V. EL CARACTER PURAMENTE LEGAL DEL MUNICIPIO.-VI. CRITICA DE LA CONCEPCION JUSNATURALISTA.-VII. ORGANIZACION MUNICIPAL EN LA LEY DE 1877.--VIII. LA UNIVERSALIZACION DEL SUFRAGIO PARA LA ELECCION DE CONCEJALES.-IX. LA ORGANIZACION PROVINCIAL.-X. LOS PROYECTOS DE REFORMA: SU ORIENTACION GENERAL. - XI. TENDENCIAS DE LOS PROYECTOS DE REFORMA DEL REGIMEN LOCAL DE LA RESTAURACION.-XII. CONCLUSION.

\section{ANTECEDENTES HISTORICOS ANTERIORES A LA ERA CONSTITUCIONAL}

Suele creerse que el Régimen local iniciado por las Cortes de Cádiz significó una ruptura de nuestra tradición municipalista y que recibió su inspiración de la Francia revolucionaria. Nada más lejos de la verdad. Toda tarea legislativa y toda labor de gobierno deben obedecer a dos exigencias: continuidad histórica y adaptación continua a los nuevos signos de los tiempos. La obra de los legisladores de Cádiz respondió a este doble imperativo. Había 
en ellos un gran respeto y una añoranza muy marcada de nuestras instituciones del pasado y un espíritu reformista nacido del deseo y de la necesidad de recoger las aspiraciones de una nueva sociedad muy diferente de la medieval, tan ensalzada por los estudios de nuestro Derecho histórico, pero que, en tres siglos de absolutismo, había sufrido una inmensa decadencia hasta llegar a una práctica desaparición.

«Nada ofrece - decía el Discurso preliminar del Proyecto de Constitución- la Comisión en su Proyecto que no se halle consignado del modo más auténtico y solemne en los diferentes cuerpos de la legislación española, sino que se mire como nuevo el método con que ha distribuido las materias, ordenándolas y clasificándolas para que formasen un sistema de ley fundamental y constitutivo en el que estuviese contenido con enlace, armonía y concordancia, cuanto tienen dispuesto las leyes fundamentales de Aragón, de Navarra y de Castilla en todo lo concerniente a la libertad e independencia de la Nación, a las fuerzas y obligaciones de los ciudadanos, a la dignidad y autoridad del Rey y de los Tribunales, al establecimiento y uso de la fuerza armada y al método económico y administrativo de las Provincias".

El título VI de la Constitución -dedicado al "gobierno interior de las Provincias y de los pueblos"- era calificado por MarTfNez MARINA de excelente. "Los dos capítulos de que consta - decíaestán sembrados de máximas utilísimas para el gobierno político y económico de las Provincias y pueblos comprendidos en ellas. Todo se encamina a proteger las libertades y derechos de los cuerpos municipales, a proporcionarles riqueza, abundancia y comodidad y a promover la opinión, el decoro y engrandecimiento de estas pequeñas sociedades, de cuya prosperidad está como colgada la de toda la Nación. Con este objeto - añadía - se ven aquí renovadas las antiguas ideas e instituciones de Castilla, que tanto contribuyeron a la exaltación de sus Concejos y Ayuntamientos, y condenadas para siempre tan destructoras máximas con que el despotismo y arbitrario gobierno de los precedentes siglos logró extinguir el espíritu público, envilecer, abatir los pueblos y reducirlos a un estado de opresión y de esclavitud».

El CONDE DE TORENo aseguraba que «en España, sobre todo en Castilla, había sido muy democrático el gobierno de los pueblos, siendo los vecinos los que nombraban sus Ayuntamientos. Fuese alterando este método en el siglo $\mathrm{xv}, \mathrm{y}$ del todo se vició durante la 
dinastía austríaca, convirtiéndose, por lo general, aquellos oficios en una propiedad de familia, y vendiéndolos y enajenándolos con profusión la Corona». Y respecto a las Diputaciones, afirmaba que se formaron a ejemplo de las de Navarra, Vizcaya y Asturias.

En relación con la falta de sentido histórico que se imputaba a nuestros "doceañistas», decía el señor Hinojosa en el Senado, contestando al señor MAESTRE: «Había en las Cortes de Cádiz hombres de gran cultura histórica, como Dou, CAPMANY, MuÑoz TORRERO y ARGÜELlES, y no cito sino los más importantes de los que ahora vienen a mi memoria. El norte y guía que tuvieron para la reforma, que llevaron a cabo en este punto, fue la restauración del sistema vigente en nuestros Municipios de la Edad Media castellana, cuya brillante organización había sido magistralmente expuesta pocos años antes por MARTínez MARINA en su conocido y célebre Ensayo histórico-crítico sobre la antigua legislación de los reinos de León $y$ Castilla».

Lamentaba MAURA la injerencia en la vida municipal -a partir sobre todo del siglo xIV - del Poder real, en cuyas manos "pereció toda autonomía concejil», "fueron los oficios enajenados; las varas y funciones municipales se compraban y vendian", transmitiéndose a título de perpetuidad hereditaria, "perdiéndose... hasta la memoria de lo que había sido el Concejo libre en los comienzos de la Edad Media».

\section{LA DEMOCRACIA MUNICIPAL A PARTIR} DE LA CONSTITUCION DE CADIZ

El propio ilustre estadista afirmaba que «la Constitución de 1812 trajo a nuestro moderno Derecho los Ayuntamientos electivos en lugar de aquellos que teníamos formados por Regidores perpetuos, por Regidores que habían comprado sus cargos, por Delegados del Poder real, por las personificaciones de todos los abusos y de todas las rapiñas. Acabar con todo esto y sustituirlo por Concejales electivos, por Regidores electivos, no era corto empeño y puede decirse que no se ocupó la Constitución de otra cosa».

FERNANDo VII restableció en 1814 el régimen absolutista. Tornóse en 1820 al régimen político y local establecido en 1812. El Real Decreto de 23 de julio de 1835 reafirma la naturaleza electiva de los cargos concejiles. La Constitución de 1837 se preocupó de 
dar a los Ayuntamientos y Diputaciones carácter electivo. La Constitución de 1845, al distinguir entre Alcaldes y Ayuntamientos, afirmando que estos últimos serán nombrados por los vecinos a quienes la Ley confiera este derecho, parece querer dejar a la iniciativa gubernamental amplio campo en la designación de Alcaldes. La Ley de Ayuntamientos de 1845 permitió al Gobierno nombrar Alcaldes-Corregidores. Las Constituyentes de 1854 afrontaron el estudio del Régimen local, pero su obra no llegó a incorporarse al Derecho positivo. Sus principios eran: 1) Electividad de Alcaldes y Concejales con representación de minorías; 2) Formación de los presupuestos por los Ayuntamientos con intervención de asociados en número duplo de los Concejales, los cuales intervienen también en la aprobación de cuentas; 3) Acuerdos ejecutivos de los Ayuntamientos salvo el requisito de aprobación superior en caso de reclamación, y 4) Garantías en caso de suspensión de Alcaldes y Concejales.

\section{EL REGIMEN LOCAL DE LA REVOLUCION DE 1868}

Con la revolución de septiembre del 68 se inicia una etapa en la que deben distinguirse el período provisional representado por la Circular de 13 de octubre de 1868 convocando elecciones municipales por sufragio universal y el Decreto de $2 \cdot 1$ del mismo mes que reproducía, con leves modificaciones, las normas de 1854 y 1856, y el período constitucional que, como dice Posada, lo llena la labor de las Constituyentes del 69, llamadas a dar una expresión constitucional y legal a las tendencias democráticas inspiradoras del movimiento del 68. "La representatividad local queda, sin embargo, indeterminada en la Constitución del 69 por virtud del reenvio de sus respectivas normas a las leyes ordinarias en cuanto a las organizaciones y atribuciones de las Diputaciones y Ayuntamientos». Según la Ley municipal de 1870 , los Concejales son de tres categorías: Alcalde, Tenientes y Regidores, elegidos todos ellos por el cuerpo de vecinos o residentes.

Los expresados antecedentes son básicos para comprender el sentido del Régimen local de la Restauración. Continúa viva la tendencia centralizadora que, a despecho de la intención declarada por las Cortes de Cádiz de "restaurar el antiguo espíritu» de nuestras instituciones locales, había desconocido — sin duda porque era impo- 
sible reconstruir el pasado esplendor de nuestro Municipio medieval- las realidades autonómicas del pasado, ya lejano y un poco incierto. Antes y después de la Restauración, y desde el inicio del constitucionalismo en nuestra patria, la característica fundamental de nuestro Régimen local puede describirse con las palabras que PosADA dedica a la etapa moderada: "Uniformidad, subordinación, responsabilidad y presencia de las autoridades en todos los grados del orden jerárquico". Era difícil idear otro sistema dadas las circunstancias sociales e históricas en que advino el régimen constitucional. Como dice don Sebastián MARTín-Retortillo (1), la centralización fue necesaria para abatir un régimen de desigualdad fijado en base al territorio o a la profesión y también en el sentido de que, por vez primera, se exigía del Estado una intervención directa en la vida cotidiana.

Entre los ideales a que rendían culto los hombres de la Restauración $\mathrm{y}$, de un modo singular, el estadista que la preparó y rigió sus destinos, CANOVAS DEL CASTILLO, apenas alcanzó relieve el relativo a la vigorización y fortalecimiento de nuestro Régimen local. Preocupaban a CÁNOvas otros problemas cuya solución era entonces urgente: atraer a la monarquía encarnada por el joven rey don AlFonso XII a hombres de la derecha y de la izquierda. A las «honradas masas» que, dirigidas por PIDAL y otros prohombres del tradicionalismo, militaban en el carlismo, a los antiguos revolucionarios: CASTElar, SAGASTA, Rfos Rosas, cuyo concurso era vital para la monarquía a fin de que pudiera formarse un partido democrático de la izquierda liberal, el prestigio del nuevo régimen en el exterior a fin de que fuera apoyado por las cancillerías extranjeras, la extinción de los rescoldos de nuestras guerras. civiles y la guerra de Cuba, etc. Así se explica que en el programa del partido conservador apenas tuviera sitio el problema de las estructuras locales. La Constitución de 1876 dedicaba escasos y nada originales artículos al régimen de los Ayuntamientos y de las Diputaciones, que seguían siendo, como en el período anterior, las Corporaciones, que tenían a su cargo el gobierno de la Vida local, con arreglo a idénticos principios que las Constituciones anteriores, en especial la de 1845 .

(1) Martfo-Retortillo, Sebastián: „Presupuestos políticos del Régimen local», Revista de Administración Pública, núm. 43, enero-abril 1964. 


\section{EL REGIMEN LOCAL EN LA CONSTITUCION DE 1876}

El título $\mathrm{X}$ de la Constitución del 76 decía así: "De las Diputaciones Provinciales y de los Ayuntamientos", y los textos de los tres artículos que contenía eran los siguientes: «En cada Provincia habrá una Diputación Provincial, elegida en la forma que determine la ley y compuesta del número de individuos que ésta señale» (artículo 82). "Habrá en los pueblos Alcaldes y Ayuntamientos. Los Ayuntamientos serán nombrados por los vecinos a quienes la ley confiera este derecho" (art. 83). "La organización y atribuciones de las Diputaciones Provinciales y Ayuntamientos se regirán por las respectivas leyes. Estas se ajustarán a los principios siguientes: 1. Gobierno y dirección de los interes peculiares de la Provincia o del pueblo por las respectivas Corporaciones. 2..$^{\circ}$ Publicación de los presupuestos, cuentas y acuerdos de las mismas. 3. Intervención del Rey, y, en su caso, de las Cortes, para impedir que las Diputaciones Provinciales y los Ayuntamientos se extralimiten de sus atribuciones en perjuicio de los intereses generales y permanentes; y $4 .^{\circ}$ Determinación de sus facultades en materia de impuestos a fin de que los provinciales y municipales no se hallen nunca en oposición con el sistema tributario del Estado» (art. 84).

La reforma de nuestro Régimen local, iniciada por el Gobierno CANovas mediante el proyecto de ley presentado a las Cortes el 23 de mayo de 1876, no fue concebida - según declaración expresada del Ministro de la Gobernación, cuya firma figuraba al pie del proyecto- como una legislación "nueva", sino como una modificación de las Leyes de 20 de agosto de 1870. Las Leyes municipal y provincial de 3 de octubre de 1877 no fueron, en realidad, más que una refundición de las expresadas Leyes de 1870 y 1876. A partir de entonces, el Régimen municipal y el provincial siguieron un proceso diferente. La Ley municipal de 1877 continuó en vigor, salvo reformas parciales, hasta la Dictadura de PRIMO DE RIVERA, más concretamente hasta la promulgación del Estatuto municipal de 8 de marzo de 1924. En cambio, la Ley provincial de 1877 fue reformada sustancialmente por virtud de la de 1882. Puede, pues, decirse que el Régimen local de la primera restauración monárquica es la contenida en las Leyes municipal de 1877 y provincial de 1882.

Como caracterización general del Régimen local podemos refe- 
rirnos, con don Adolfo Posada, a «la persistencia continuada de un criterio de centralización mantenido durante todo el período constitucional», que tiene «su principal expresión geográfica en una división territorial general, que obedece a la idea generadora de someter las determinaciones locales a las necesidades de los servicios del Estado nacional» - más bien a las necesidades o pretensiones del Poder central-. Dicha división territorial fundamental, que refleja y reproduce en círculos menores la estructura misma del Estado y la composición de sus elementos (territorio y población), es la que comprende las Provincias y los Municipios. El territorio español, en efecto, se divide en Provincias, y éstas en Municipios, por obra del Poder central y según las Leyes provincial y municipal vigentes.

\section{EL CARACTER PURAMENTE LEGAL DEL MUNICIPIO}

Punto de partida del Régimen local de la Restauración es el carácter puramente legal del Municipio, que nos muestra el artículo $1^{\circ}$ de la Ley de 1877 -mera reproducción del mismo artículo de la Ley de 1870 - al definirlo como «asociación legal de todas las personas que residen en un territorio municipal». El Municipio, señalaban los comentaristas, es, por tanto, una creación legal, un producto de la voluntad del legislador, no «una formación natural, espontánea, histórica, real». No puede decirse, sin embargo, que el legislador ignorase el elemento, el sustrato sociológico del Municipio, que no otra cosa es «el pueblo», como decía la Constitución de 1812 y seguirán diciendo las Constituciones de la pasada centuria y el Código civil. Elementos esenciales, por tanto, del Municipio son, en esta definición, la población y el territorio, pero no puede decirse que sirvan para caracterizar el Municipio frente a otras comunidades territoriales, como el Estado —comunidad política por excelencia-, o las de carácter suprasoberano que existen o puedan crearse como intermedias entre el Municipio y el Estado: la Provincia, la Región, etc. Lo que determina aquí la conjugación de población y territorio es que las personas que forman la población aparecen asociadas legalmente, es decir, por virtud de la ley del Estado y que el factor territorial se concreta en una circunscripción llamada término municipal definido en la Ley como «el territorio a que se extiende la acción administrativa del Ayunta- 
miento». Lo importante aquí es poner en relación el sústrato sociológico: el pueblo con la institución jurídica creada por la ley del Estado: el Municipio. ¿Cuándo y en qué medida deberá el legislador reconocer a un "pueblo», a un núcleo urbano, a un asentamiento poblacional, el derecho a constituirse en Municipio? ¿Cuándo deberá éste ser creado por el Estado? Dos críticas opuestas han recaído sobre el concepto del Municipio - heredado, como hemos visto, del Derecho anterior- que revela la Ley de 1877. Por una parte, el atribuir al Municipio un carácter puramente legal. Por otra —en sentido opuesto-, la generosidad al atribuir el carácter de Municipio a pequeños núcleos de población carentes de toda posibilidad económica de prestar a la comunidad vecinal los servicios más indispensables en el actual nivel del curso histórico.

\section{CRITICA DE LA CONCEPCION JUSNATURALISTA}

El primer motivo de crítica lo vemos brillantemente expuesto en la Exposición de Motivos del Estatuto municipal de 1924, uno de nuestros documentos jưrídicos más notables: El Municipio... "no es hijo del legislador, es un hecho social de convivencia, anterior al Estado y anterior también, y además superior, a la ley. Esta ha de limitarse, por tanto, a reconocerlo y ampararlo en función objetiva». "Por todo ello, el nuevo Estatuto admite la personalidad municipal allí donde la naturaleza lo engendra, sin admitir requisitos de nuevo artificio, que nunca han tenido posible cumplimiento». ¿Cuáles eran esos requisitos calificados por los autores del Estatuto de artificiales? El artículo $2 .^{\circ}$ de la Ley de 1877 fijaba como circunstancias precisas en todo término municipal: $10^{\circ}$ Que no baje de 2.000 el número de sus habitantes residentes; $2 .^{\circ}$ Que tenga o se le pueda señalar su territorio proporcionado a su población; y 3.० Que pueda sufragar los gastos municipales obligatorios con los recursos que las leyes autorizan. "Subsistirán, sin embargo, los actuales términos municipales que tengan Ayuntamientos, aun cuando no reúnan las circunstancias anteriores». Continuaba este precepto el criterio mantenido desde que se inauguró en España el régimen constitucional a partir del artículo 310 de la Constitución de 1812, a euyo tenor: "Se pondrá Ayuntamiento en los pueblos que no lo tengan y en que convenga le haya, no pudiendo dejar de haberlo en los que por sí o con su comarca lleguen a 1.000 almas, 
y también se les señalará término correspondiente». Significaba este precepto una leve atenuación del de la Constituyente francesa de 1789, que alumbró de golpe 44.000 Municipios. Aun así produjo la consecuencia, no remediada en las siguientes leyes del siglo XIX, de convertir en Municipios viejos Concejos de organización sencilla y elemental. $\mathrm{Y}$ he aquí el segundo $-\mathrm{y}$ contradictorio del anteriormotivo de crítica suscitado por la Ley de 1877. Ya con anterioridad, el Proyecto de Ley de Ayuntamientos de 1860 denunciaba los graves inconvenientes que ofrecen las Municipalidades microscópicas -auténticos micromunicipios- «sin recursos para cubrir sus más perentorias atenciones». Consecuentemente, ColmeIro proponía disminuir hasta donde sea posible el número de Ayuntamientos. El lamento continúa fundadamente hasta nuestros días. Un número elevado de Municipios tiene presupuestos tan pobres que no pueden atender los servicios más elementales. Algunos ni aun siquiera pueden sostener decorosamente la organización mínima indispensable: un secretario, un subalterno, un guardia municipal... Como he dicho en otro lugar, "la ficción de personalidad municipal de estos pequeños núcleos podía mantenerse cuando sus vecinos apenas reclamaban otros servicios que los de guardería rural; administración de su patrimonio: un prado, una dehesa boyal; reparto de la contribución territorial; conservación de una fuente, de un lavadero, de un abrevadero. Pero es difícil de sostener desde que se evidencia la natural aspiración de esa población campesina a alcanzar formas de vida similares a las que el progreso técnico ha proporcionado al hombre de la ciudad. Agrava el problema la curva demográfica decreciente de los pueblos y aldeas, determinada por la natural atracción que ejerce el medio urbano - más cómoda la vida, más altos los jornales- y aumentada por la sensible exportación de brazos hacia países que gozan de un alto nivel de desarrollo industrial».

La prueba de que no se trataba de requisitos de mero artificio está en que la Ley de Régimen local vigente - texto refundido de 24 de junio de 1955- dice en su artículo 15: "Para crear nuevos Municipios será necesario que cuenten con población, territorio y riqueza imponible bastante para sostener los servicios municipales obligatorios, utilizando los recursos que las leyes autorizan". La conjugación de estos tres factores: cifra de población, extensión territorial mínima y riqueza suficiente, queda indeterminada en la Ley. La de 1877 fijaba, al menos, una cifra de población 
imprescindible, si bien desvirtuaba, prácticamente, esa exigencia al declarar subsistentes los términos municipales establecidos, aun cuando careciesen de las circunstancias exigibles para el futuro.

En la legislación comparada se ha ido imponiendo cada día más la exigencia de una cifra de población mínima para gozar de la consideración legal de Municipio. Este criterio ocasionó en Suecia hace menos de un cuarto de siglo la supresión de gran número de Municipios. En Portugal no hay, prácticamente, Municipios menores de 4.000 habitantes. El mismo Estatuto municipal, a pesar de que su jugosa Exposición de Motivos está inspirada por el romanticismo municipalista de aquella época, suscitado por el florecer del estudio de nuestras instituciones jurídicas históricas a partir de las investigaciones y esclarecimiento del sabio profesor Hinojosa, se alude a la realidad de que muchos Municipios «carecen de recursos, hasta el punto de absorberlos casi todos el sueldo de su Secretario" y se admite como solución la agrupación forzosa de Municipios, buena prueba de que la realidad no suele acomodarse a los cantos líricos, a unos ideales inasequibles.

\section{ORGANIZACION MUNICIPAL EN LA LEY DE 1877}

La organización administrativa municipal era en la Ley de 1877 «uniforme y simétrica en sus principios generales y en sus detalles» (PosADA) (2). Según su artículo 30, el gobierno interior de cada término municipal será encomendado a un Ayuntamiento compuesto de Concejales divididos en tres categorías: Alcaldes, Tenientes y Regidores. El Ayuntamiento será elegido por los residentes en el término que tengan derecho electoral, según el artículo 40, y en la forma que determinan las leyes. A tenor del artículo 40, eran electores «los vecinos cabezas de familia con casa abierta que lleven dos años, por lo menos, de residencia fija en el término municipal y vengan pagando por bienes propios alguna cuota de contribución de inmuebles, cultivo y ganadería o de subsidio industrial y de comercio, con un año de anterioridad a la formación de listas electorales, o acrediten ser empleado civiles del Estado, la Provincia o el Municipio en servicio activo, cesantes con haber por clasificación, jubilados o retirados del Ejército y Armada. También serán

(2) POSADA, Adolfo: Evolución legislativa del Régimen local en España, pág. 291. 
electores los mayores de edad que, llevando dos años por lo menos de residencia en el término del Municipio, justifiquen su capacidad profesional o académica por medio de título oficial. En los pueblos menores de 100 vecinos, todos ellos serán electores, sin más excepciones que las generales que establece el artículo $2 .^{\circ}$ de la Ley electoral de 20 de agosto de 1870 ».

\section{LA UNIVERSALIZACION DEL SUFRAGIO PARA}

\section{LA ELECCION DE CONCEJALES}

Pero dicho sistema de sufragio restringido terminó el año 1890 , cuando el Gobierno liberal, presidido por SAGASTA, estableció el sufragio universal, extensivo a la Vida local lo mismo que a la del Estado, por virtud del Real Decreto de 5 de noviembre de dicho año, que en su artículo $10^{\circ}$ otorgó la cualidad de electores para Diputados provinciales y Concejales a todos los españoles varones mayores de veinticinco años que se hallen en el pleno goce de sus drechos civiles y sean vecinos de un Municipio en el que cuenten dos años, al menos, de residencia.

La Ley electoral de 8 de agosto de 1907 -debida a la iniciativa de un Gobierno presidido por don Antonio MaURA- consagró el sufragio universal, igual, directo y secreto, mediante normas dirigidas a purificar el sufragio y que han estado en vigor hasta el advenimiento de la República, a consecuencia de unas elecciones municipales verificadas, precisamente, en cumplimiento y al amparo de dicha Ley.

Preside el Ayuntamiento y asume su representación unitaria y su Poder ejecutivo el Alcalde, quien ostenta también la representación del Poder central, y es, por tanto, órgano de comunicación con éste a través del Gobernador civil de la Provincia. Según el artículo 49 de la Ley citada, los Ayuntamientos eligen de su seno a los Alcaldes y Tenientes de Alcalde. El Rey, sin embargo, puede nombrar de entre los Concejales los Alcaldes de las capitales de Provincia, cabezas de Partido judicial y pueblos de igual o mayor vecindario que aquéllas dentro del mismo Partido con más de 6.000 habitantes. El Alcalde de Madrid es de libre nombramiento del Rey, que puede, además, nombrar los Tenientes de Alcalde, pero debiendo ser éstos elegidos del seno de la Corporación municipal. Sustituye al Alcalde el Teniente de Alcalde, y, si hay más de uno, el orden de su enumeración determina el sustituto. Dependen del 
Teniente respectivo los Alcaldes de barrio nombrados por el Alcalde y colocados al frente de los distintos barrios en que los distritos se dividen.

\section{LA ORGANIZACION PROVINCIAL}

Respecto de la organización provincial, la Ley de 29 de agosto de 1882 dispone que «el territorio de la Nación española en la Península e islas adyacentes se divide para su administración y régimen en Provincias». Pero, en realidad, la Provincia es más que una mera circunscripción del Estado para el cumplimiento de sus fines, como lo demuestra el artículo 74 al atribuir con carácter exclusivo a las Diputaciones Provinciales «la administración de los intereses peculiares de las Provincias respectivas», y el 78 al disponer que los acuerdos tomados por la Diputación Provincial «se efectuarán, desde luego, sin perjuicio de los recursos establecidos en esta Ley». Había, por tanto, base suficiente para distinguir los dos aspectos que, todavía hoy, tiene la Provincia: como circunscripción del Estado para el cumplimiento de sus fines y como Entidad local de fines propios. Es en la Ley provincial de 1870 donde, al decir de PoSADA, se consagra la sustantividad de la Provincia, que deja de ser una mera división territorial para convertirse en un expresión local, o, como dice GaRcfa DE ENTERRf́a, donde más claramente se inicia el camino hacia un pleno reconocimiento de la Provincia como persona jurídica pública con un cierto margen de autonomía administrativa, o, en otros términos, cuando se reconoce a la Provincia como Entidad local propiamente tal, debiendo observarse que en este proceso la Ley de 1882 supone un cierto retroceso en esta vía iniciada en la Ley de 1870.

El artículo $5 .^{\circ}$ de la Ley provincial de 1882 afirma que el régimen y administración de las Provincias corresponde: 1. Al Gobierno; $2^{\circ}$ A la Diputación Provincial, y 3. $\mathrm{A}$ la Comisión Provincial. Pero el artículo 14 declara terminantemente que el Gobierno de las Provincias corresponde al Gobernador como representante del Gobierno de Su Majestad.

Aspecto importante es el relativo a la composición de las Diputaciones Provinciales. Según el artículo $7 .^{\circ}$, «la Diputación Provincial se compone de los Diputados elegidos por los habitantes de la Provincia, a quienes la presente Ley reconoce este derecho y en la forma que la misma Ley y la electoral determinen». Habrá en cada 
Provincia -dice el artículo $80^{\circ}$ - el número de Diputados que resulte de la agrupación de cada dos Partidos judiciales precisamente colindantes en un distrito que elegirá cuatro Diputados. Cuando el número de Partidos judiciales sea impar, aquel que cuente mayor número de habitantes formará por sí un solo distrito, que elegirá cuatro Diputados. En las Provincias que tengan seis, siete u ocho Partidos judiciales se formarán cinco agrupaciones electorales, y para ello constituirán distritos por sí solos los Partidos judiciales de mayor número de habitantes. Cuando las Provincias se compongan de cinco o de menos Partidos judiciales, cada uno formará por sí solo distrito, eligiendo cuatro Diputados.

En el Régimen provincial de 1882 tiene importancia excepcional la Comisión Provincial, compuesta por tantos Diputados como distritos y elegida en votación secreta por todos los que integran la Corporación. Definido como cuerpo administrativo, corresponde a la Comisión la ejecución y preparación de los acuerdos de la Diputación, la resolución interna de asuntos urgentes encomendados por la Diputación, etc.

Los Diputados provinciales son elegidos por sufragio universal directo con voto secreto con representación de minorías; cada elector vota'tres candidatos.

El cargo de Diputado provincial es gratuito y honorífico y está sujeto a responsabilidad; una vez aceptado no es renunciable sin causa y es incompatible con todo otro cargo del Estado, Provincia - Municipio, salvo con el de Catedrático de Universidad, Escuela Normal e Institutos. Se determinan cuidadosamente las incapacidades para ser Diputado, y, como regla general, puede ser elegido todo el que quiera serlo a Cortes y sea natural de la Provincia o lleve en ella cuatro años consecutivos de vecindad. La Diputación se renueva por mitad cada cuatro años. La elección de Diputados provinciales se habrá de celebrar en la primera quincena del tercer mes del año económico.

Las Diputaciones gozan de personalidad, pero carecen de autonomía. Sus atribuciones son las que taxativamente les otorgan las leyes y tienen un doble carácter, según les competan como Corporaciones representativas de las Provincias o como superiores jerárquicos de los Ayuntamientos, cuyos acuerdos servirán y a los cuales giran visitas de inspección.

Los acuerdos de la Diputación pueden ser suspendidos en ciertos casos por el Gobernador, contra cuya resolución cabe recurso 
ante el Gobierno, y contra la resolución de éste cabe interponer recurso contencioso.

Se trata, como vemos, de un sistema administrativo jerárquico: Gobierno central, Gobernador civil, Diputación y Ayuntamiento.

El Gobernador es el Jefe de la Administración provincial, y en tal concepto tiene las facultades siguientes: $1 .^{\text {a }}$ Presidir con voto la Diputación Provincial y la Comisión. 2. ${ }^{a}$ Comunicar y ejecutar los

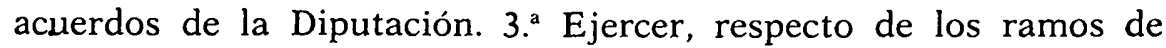
Gobernación y Fomento, la autoridad que determinan las leyes y reglamentos, y en la administración económica provincial y municipal, las atribuciones que se le confieren por las disposiciones legales. 4. ${ }^{a}$ Inspeccionar las dependencias de la Provincia y las de los Ayuntamientos, cuidando de que se cumplan así las leyes y disposiciones generales como los acuerdos de la Diputación y de la Comisión Provincial, y procurando que éstas observen y cumplan su ley. 5." Suspender los acuerdos de la Diputación y de la Comisión cuando proceda, dando cuenta al Gobierno dentro de las cuarenta y ocho horas y poniéndolo también en conocimiento de la Diputación.

\section{LOS PROYECTOS DE REFORMA: SU ORIENTACION GENERAL}

Apenas entrada en vigor la Ley provincial de 1882 se desarrolló un período de proyectos de reformas que, iniciado por el que, en diciembre de 1882, presentó al Senado el Ministro de la Gobernación, don Venancio GoNZÁlez, culminó en los proyectos muy acabados y perfectos de Maura (1907) y Canalejas (1912). Podemos recordar: los dos de MORET, presentados en enero de 1884, para reforma de la Ley municipal y de la Ley provincial, respectivamente; el de "Gobierno y Administración local», de RoMERo ROBLEDo, de diciembre de 1884; el de Ley municipal, de don Venancio GonzÁI.EZ, de 1886, reproducido en 1887, 1888 y 1889 junto con el de reforma parcial de la Ley provincial; el de Ley del Gobierno y Administración local de 1891, preparado con especial cuidado y detenido estudio, de Silvela-SÁNCHEZ DE TOCA, que no llegó a presentarse a las Cortes; el de 1893-1894, mediante unas bases que aprobó el Senado para una nueva refundición de las leyes provincial y municipal; el de DATO, de diciembre de 1899, modificando la organización provincial y municipal, precedido del de descentrali- 
zación administrativa, presentado en octubre del mismo año por Silvela; el de 1901, de GonZÁlez; el de 1902, de MoreT; el de mayo de 1903, de MAURA, estableciendo las bases para la reforma de la Administración local, que fue discutido y aprobado en el Senado, dándose cuenta al Congreso; el de GonzÁlEZ BESADA, sobre reforma de la Hacienda municipal de 1905; el de Romanones, de 1906, y, en fin, los antes citados de Maura, de 1907, y Canalejas, de 1912, que requieren estudio especial.

Establecía PosAda una relación entre la consolidación del régimen de 1870 y 1882 y la reforma perseguida y preparada en los proyectos posteriores, que se traducía en una práctica seguida con la posible apreciación consiguiente de los defectos del sistema sostenido desde 1812 y la diferenciación indispensable para que llegaran a producirse las diversas aspiraciones de mejora con alguna aspiración y relieve. A juicio del ilustre tratadista, en el período de actuación de las leyes orgánicas de 1877 y 1882 se había completado un proceso histórico de restauración doctrinal y real de la Vida local, merced a un progreso de la cultura nacional asociado a la labor investigadora de beneméritos especialistas, al régimen de libertad de expansión de la Revolución del 68 y a la meritable renovación de los ideales políticos en un sentido democrático y social.

La reforma proyectada en 1907 propendia, según PosADA (3), a recoger en una solución armónica dos tendencias capitales: la tradicionalista, de significación histórica más que política, y la progresista o de aceptación de las aspiraciones modernas, a las que debian apegarse ciertos movimientos regionales de verdadera fuerza, como el catalán. El proyecto de Canalejas perfeccionó el de MAURA, del que no se separó mucho, con un criterio transaccional muy positivo en aras de la concordia.

\section{TENDENCIAS DE LOS PROYETOS DE REFORMA DEL REGIMEN LOCAL DE LA RESTAURACION}

Como tendencias generales manifestadas en la elaboración de la reforma del Régimen local, don Adolfo PoSADA distinguía las siguientes:

1. Integración del régimen municipal y provincial en un Régimen local. (Esto no se logrará hasta la Ley de Bases de 17 de julio

(3) Obra citada, pág. 498. 
de 1945, desarrollada en la articulada de 1950 y en texto refundido actualmente vigente de 1955).

2." Consagración legal de la variedad de Municipios y de formaciones locales. Tratamiento especial de los Municipios pequeños mediante su fundición con los más inmediatos y afines, conservando su administración especial y su personalidad jurídica para sus derechos peculiares, su agrupación con los limítrofes, etc. Diverso tratamiento legal, en especial para la elección de Concejales, estableciéndose el Concejo abierto - aunque sin darle este nombrepara los menores de 1.000 habitantes; uniones y comunidades o mancomunidades municipales.

3. ${ }^{\mathrm{a}}$ Descentralización $y$ diferenciación de funciones con cierta tendencia hacia la autonomía y subordinación excepcional del Municipio al Estado mediante el régimen de tutela.

4. ${ }^{\mathrm{a}}$ Reconocimiento de la vida municipal moderna y admisión de la municipalización.

5. Incorporación a la vida municipal de los elementos sociales: vocales natos, voto corporativo.

6. ${ }^{\mathrm{a}}$ Reorganización de las instituciones de gobierno municipal en el sentido de diferenciar el organismo representativo del Municipio en una Corporación amplia de función intermitente -el Ayuntamiento- y una Comisión o Junta de carácter permanente.

7." Tendencia a resucitar las Regiones.

La integración del régimen municipal y provincial en un solo texto, mediante un tratamiento unitario del Régimen local, tiene sus primeros intentos en el proyecto de ROMERO ROBLEDO de 1884, titulado de "Gobierno y Administración local»; en el de SAGASTA, de 1893, refundidor de las Leyes provincial y municipal, y en el Proyecto de Ley de Descentralización administrativa, de Silvela, de 1899, inspirado en idéntica idea unitaria. Pero donde se muestra con fuerza es en el "Proyecto de Ley y Bases para la reforma de la Administración local» que, al poco tiempo de asumir la cartera de Gobernación en un Gabinete, Silvela presentó al Senado en la sesión de 27 de mayo de 1903, en la cual afirmó que ligaba su vida ministerial a «la suerte de este proyecto». El solo título del proyecto indicaba la idea integradora que lo inspiraba, y que no varió nunca en los propósitos reformadores del insigne estadista, y que éste razonaba diciendo que «aun en el orden especulativo» no había conseguido "ver aislado el pensamiento de una reforma muni- 
cipal sin la reforma provincial..., porque debajo del régimen provincial existente cualquier reforma de la' Ley municipal había de fracasar sin remedio». También Canalejas aceptó el criterio unificador en su Proyecto de Ley de Bases sobre Régimen local, leído en la sesión del Congreso del 15 de octubre de 1912 por el Ministro de la Gobernación, don Antonio BARRoso, y cuya elaboración fue casi totalmente obra de don Adolfo G. Posada. Extrañamente, CALvo Sotelo, discípulo predilecto de MAURA, no intentó la integración del Régimen local. Por el contrario, redactó separadamente el Estatuto municipal (1924) y el provincial (1925). Tampoco la Segunda República aceptó el criterio unificador, limitándose a elaborar la Ley municipal de 1935. Habrá que esperar a la Ley de Bases de 17 de julio de 1945 para que la concepción unitaria triunfe.

Respecto a la consagración legal de la variedad de Municipios y de formaciones locales, es decir, al abandono del uniformismo en el tratamiento legal de las Entidades locales, que JoRDANa DE Pozas considera como una de las tendencias europeas del Régimen local evidenciadas desde los inicios de la segunda postguerra mundial, dando lugar a diversos tipos de Entidades municipales: la capital del Estado, la gran ciudad, el Municipio urbano, el Municipio rural y las Entidades locales menores, es notorio que en nuestra legislación, ni antes de la Restauración, ni durante ésta (comprendiendo en la misma la Regencia y reinado de Alfonso XIII), ni después de ella, ha tenido acogida la distinción del Municipio urbano y el Municipio rural. Ha habido, simplemente, una ecuación entre la cifra de población municipal y el número de Concejales de cada Ayuntamiento, algunas singularidades en la elección del Alcalde y la muy relevante modalidad del Concejo abierto para los Municipios menores de 1.000 habitantes. Respecto a la capital del Estado y las grandes ciudades, sólo con posterioridad al texto articulado de 1955 han tenido efectividad regímenes especiales en leyes también especiales. En cambio, las Entidades locales menores fueron ya intuidas en la Ley municipal de 2 de octubre de 1877 al decir en su artículo 90 que «los pueblos que, formando con otro término municipal, tengan territorio propio, aguas, pastos, montes o cualesquiera derechos que les sean particulares, conservarán sobre éllos su administración particular». Con este fin se les dota en el mismo artículo de una Junta compuesta de un Presidente y de dos o de cuatro vocales elegidos directamente por los vecinos. El proyecto de MAURA de 1907 avanzó más al decir que «los poblados, aldeas y 
caseríos anejos que tengan territorio propio, aguas, pastos, montes o cualesquiera derechos peculiares, conservarán sobre ellos su administración particular por medio de Juntas de vecinos elegidas directamente por los electores del Municipio con residencia en el anejo» (art. 31), y "dotar a dichos anejos de capacidad jurídica para adquirir, conservar o ejercitar acciones" (art. $4 .^{\circ}$ ). El Estatuto municipal de 1924, consecuente con su inspiración jusnaturalista y su reconocimiento de la personalidad municipal «allí donde la naturaleza la engendra», dio la flamante denominación de "Entidades locales menores» a los "anejos, parroquias, lugares, aldeas, caseríos y poblados que, dentro de un Municipio y constituyendo núcleo separado de edificaciones, forman un conjunto de personas y bienes con derechos e intereses peculiares y colectivos, diferenciables a los generales del Municipio». Y esta revitalización, infundadamente optimista de la inframunicipalidad, pasó a la Ley municipal de 1935 y a la Ley de Bases de 17 de julio de 1945.

La descentralización, orientada hacia una autonomía de las Corporaciones locales y a un robustecimiento del selfgovernment. En la Ley de 1877 los acuerdos municipales podían ser revocados por la autoridad gubernativa, la cual convertía a los Ayuntamientos «en simple rueda del engranaje administrativo del Estado", como se dice en la Exposición de Motivos del Estatuto municipal. En el proyecto de MaURa los acuerdos de las Corporaciones municipales, en los límites señalados a la exclusiva competencia municipal, causaban estado. Contra ellos no cabía otro recurso que el contenciosoadministrativo en instancia única ante el Tribunal provincial, motivado bien por tratarse de derecho del reclamante o bien por infracción de disposiciones con fuerza legal, cuya observancia pidiera cualquiera de los vecinos, aunque no constase agraviado individualmente en su derecho. Este sistema fue consagrado por el Estatuto municipal y, desde entonces, ha quedado definitivamente incorporado a nuestro Derecho.

La municipalización de servicios tiene, al decir de MARqués CAR$\mathrm{B} \sigma$, precedentes en el siglo $\mathrm{XV}$ y siguientes con los Abastecedores $\mathrm{u}$ Obligados - de la carne, del tocino, del aceite-, que se ofrecían mediante posturas y bajo fianza y se obligaban a tener abastecido al vecindario de un determinado producto por el tiempo que se señalaba y al precio convenido (4). La legislación española del siglo

(4) Marqués Carbo, Luis: El Derecho local español, 1, pág. 749. 
pasado no la prohibia, pero tampoco la preveía. Varios Reales Decretos de 1905 autorizaron la municipalización de servicios de mataderos, mercados. Una Real Orden de 23 de julio de 1907 autorizó la municipalización del gas. El proyecto de MAURA, de 1907, declaró de la exclusiva competencia de los Ayuntamientos la municipalización de servicios que antes vinieran prestándose por particulares, sociedades o empresas, y el proyecto de CANALEJas, de 1912, recogió este criterio. Pero fue el Estatuto municipal el primer texto legal que consagró la municipalización de servicios, recogida después con no muy nuevas modalidades en las sucesivas leyes de Régimen local y ampliada en la vigente en la provincialización de servicios.

Por lo que se refiere a la incorporación a la vida municipal de los elementos sociales, ya en el proyecto de SILvela-SÁNCHEZ DE TocA, de 1891, una tercera parte de los Concejales en los Municipios de más de 100.000 habitantes se elegía proporcionalmente por compromisarios nombrados por los mayores contribuyentes (reminiscencia del sufragio censitario) y por las Corporaciones que tuvieran su residencia principal en el Municipio y disfrutasen de derechos electorales (iniciación de un sufragio corporativo). MORET recogió esta tendencia en su proyecto de 1902 al reservar una quinta parte de los Concejales a la elección por Colegios especiales de patronos y obreros. Pero es don Antonio Maura quien, en su proyecto de 1903 con sus Concejales natos y en el de 1907 con sus Concejales-delegados, intenta adjuntar de una manera sistemática y completa a los Concejales elegidos por sufragio universal a los Concejales de representación corporativa. CANALEJAS perfeccionó el sistema distribuyendo estos últimos en tres tercios que respondiesen a la conveniencia de representar por iguales partes a los patronos, los obreros y a las profesiones liberales. El Estatuto municipal recogió con algunas variantes esta innovación pretendida por $\mathrm{C}_{\mathrm{A}}$ NALEJAS.

La diferenciación de Ayuntamiento pleno y Comisión permanente para la distribución orgánica de las facultades propias del gobierno municipal apunta ya en los proyectos de 1884, 1891 y 1894 , $\mathrm{y}$, después de ser defendido inteligentemente por MORET en su proyecto de 1902, fue recogido, en su proyecto de 1903, por MAURA, quien afirmó que el sistema «se reduce a concentrar en pocas manos la acción ejecutiva y a dar a la Asamblea electiva el carácter de soberanía en lo que le atañe». La idea se perfecciona en el pro- 
yecto de 1907, en el que la Comisión permanente es un Cuerpo colegiado reducido en el que se busca la máxima eficacia, y, a través del proyecto de Canalejas, de 1912, pasa esta diferenciación de Pleno y Permanente, que ha sido recogida en numerosas legislaciones extranjeras, al Estatuto municipal y a las leyes municipales de la República y del Caudillaje.

Finalmente, la tendencia a resucitar las Regiones, tras los fracasos de los proyectos de regionalización de MORET (1884) y SiLVELA-SÁNCHEZ DE TOCA (1891), originó la admisión en los proyectos de MAura y Canalejas de la facultad de mancomunarse otorgada a las Diputaciones Provinciales, recogida en el Real Decreto del Gobierno Dato de 18 de diciembre de 1913, a cuyo amparo se constituyó la Mancomunidad catalana en 1914.

\section{CONCLUSION}

La Ley municipal de 1877 fue la única que rigió durante la Restauración de la monarquía constitucional, aun extendiendo esa denominación - Restauración - a todo el período a que se extiende la vigencia de la Constitución de 1876, es decir, incluyendo la Regencia y el reinado constitucional de don ALFONSo XIII, que termina el 13 de septiembre de 1923 con el establecimiento de la Dictadura de Primo DE Rivera. Dicha Ley de 1877 tiene escasa originalidad y es, en realidad, una refundición y adaptación a la monarquía restaurada de la Ley de 1870, promulgada durante el período revolucionario, que se inicia con la "gloriosa» de septiembre de 1868. Pero desde los primeros años de vigencia de la Ley de 1877 se proyecta su reforma, que, por la inestabilidad de los Gobiernos y los Parlamentos y lo enconado de las luchas políticas, no tendrá efectividad hasta el Estatuto municipal de 1924, promulgado bajo la Dictadura. En él se recogen las innovaciones más importantes que se intentaron durante cuarenta y siete años y se intensificaron en la primera década del actual siglo, es decir, desde el primer proyecto de MaURa hasta el asesinato de Canalejas, en noviembre de 1912. El propio Calvo Sotelo, autor del Estatuto municipal, confiesa en su Exposición de Motivos, que "gran parte de las innovaciones que contiene el Estatuto municipal están abonadas por el estudio previo y la coincidencia expresiva de hombres pertenecientes a todos los sectores doctrinales". 